\title{
Evolutionary roots of arginase expression and regulation
}

\author{
Jolanta Maria Dzik* \\ Department of Biochemistry, Faculty of Agriculture and Biology, Warsaw University of Life Sciences - SGGW, Warszawa, Poland
}

\section{Edited by:}

Charles Dudley Mills, BioMedical Consultants, USA

Reviewed by:

Andrew Tasman Hutchinson, University of Technology Sydney, Australia

Dalil Hannani, APCure SAS, France

*Correspondence:

Jolanta Maria Dzik, Department of Biochemistry, Faculty of Agriculture and Biology, Warsaw University of Life Sciences - SGGW, 159

Nowoursynowska, Warszawa 02-776,

Poland

e-mail: jolanta_dzik@sggw.pl
Two main types of macrophage functions are known: classical (M1), producing nitric oxide, $\mathrm{NO}$, and $\mathrm{M} 2$, in which arginase activity is primarily expressed. Ornithine, the product of arginase, is a substrate for synthesis of polyamines and collagen, important for growth and ontogeny of animals. M2 macrophages, expressing high level of mitochondrial arginase, have been implicated in promoting cell division and deposition of collagen during ontogeny and wound repair. Arginase expression is the default mode of tissue macrophages, but can also be amplified by signals, such as IL-4/13 or transforming growth factor $\beta$ (TGF- $\beta$ ) that accelerates wound healing and tissue repair. In worms, the induction of collagen gene is coupled with induction of immune response genes, both depending on the same TGF$\beta$-like pathway. This suggests that the main function of M2 "heal" type macrophages is originally connected with the TGF- $\beta$ superfamily of proteins, which are involved in regulation of tissue and organ differentiation in embryogenesis. Excretory-secretory products of metazoan parasites are able to induce M2-type of macrophage responses promoting wound healing without participation of Th2 cytokines IL-4/IL-13. The expression of arginase in lower animals can be induced by the presence of parasite antigens and TGF- $\beta$ signals leading to collagen synthesis. This also means that the main proteins, which, in primitive metazoans, are involved in regulation of tissue and organ differentiation in embryogenesis are produced by innate immunity. The signaling function of $\mathrm{NO}$ is known already from the sponge stage of animal evolution. The cytotoxic role of NO molecule appeared later, as documented in immunity of marine mollusks and some insects. This implies that the $\mathrm{M} 2$-wound healing promoting function predates the defensive role of NO, a characteristic of M1 macrophages. Understanding when and how the M1 and M2 activities came to be in animals is useful for understanding how macrophage immunity, and immune responses operate.

Keywords: arginase, evolution, hemocytes, M1/M2 macrophages, nitric oxide synthase, parasites, TGF- $\beta$, wound healing

Vertebrate macrophages play an innate defense role against various pathogens. They perform phagocytosis, bacterial killing, defend against protozoan and metazoan parasites and take part in wound healing. To fulfill such protective functions, "resting" macrophages must be activated. Two main types of macrophage functions have been identified: classical (M1), producing nitric oxide (NO), and M2-type, in which arginase (producing the healing molecule, ornithine) is expressed $(1,2)$. These responses from macrophages demand different cascades of biochemical reactions, which are regulated by specific sets of cytokines. M1 type can be stimulated by pathogen associated molecular patterns (PAMP) or amplified by T cell cytokines, such as IFN- $\gamma$. In contrast, M2 activity is the resident tissue type, and can be amplified by molecules such as IL-4, IL-13, and transforming growth factor- $\beta$ (TGF- $\beta$ ). Local signals polarize macrophages to an appropriate response. These immune functions are indispensible for both life of an individual and lasting of a species. It is apparent that macrophages, as well as other cells of innate immune response acting in vertebrates, have their deep evolutionary roots in cells serving similar function in ancestral invertebrates. Various names have been used to define such cells in different invertebrate groups, i.e., hemocyte, coelomocyte, amebocyte, or plasmatocyte, collectively named immunocytes (3).
However, regardless of the terminology, they perform the same immune functions, and are of similar morphology.

Macrophages, the professional phagocytic cells in humans, derive from circulating monocytes or by self renewal in the tissues, and acquire new morphological and physiological characteristics according to the organs and microenvironments, in which they settle. However, this unitarian origin is uncertain for circulating and tissue phagocytes (immunocytes) in invertebrates (3). Immunocytes and macrophages share ability to be activated by non-self material and to react through the release a variety of biologically active molecules such as cytokines, NO, reactive oxygen species, hydrolytic enzymes, and neuroendocrine mediators. In vertebrate immunity, various organs and immune cells are involved, while all the molecules determining invertebrate immune response are harbored in the immunocytes. From the perspective of this review, the multifunctional role of invertebrate cells seems instructive in respect to its inheritance by vertebrates.

In search for selection pressure for macrophage differentiation into M1 and M2 phenotypes, it is tempting to look back to recognize which of the functions of M2 macrophages is aligned straight with invertebrate immunocytes and is found possibly in the most primitive invertebrates. Accumulated evidences 
strongly suggest that a primary function of M2 macrophages is tissue repair and wound healing $(4,5)$. This process demands polyamines and collagen synthesis what strongly depend on arginase activity (6).

\section{ANIMAL ARGINASES}

Arginase (amidinohydrolase, EC 3.5.3.1) is an ubiquitous enzyme found in bacteria, yeasts, plants, invertebrates, and vertebrates. Some bacteria possess a related enzyme, agmatinase (Escherichia coli or Methanobacterium, also Methanococcus), which belong to Archaebacteria. Agmatinase produce putrescine and urea, arginase ornithine and urea. Plant arginases are closer to the agmatinase clade than to the animal one $(7,8)$. Agmatinases origin predates that of arginases and the latter would have appeared in the Bacteria by recruitment of a wide specificity agmatinase and then its transfer to an eukaryotic cell (according to Sekowska et al. perhaps through mitochondria) (8).

Most microorganisms and invertebrates studied to date have only one type of arginase (9). Arginases from plants and ammoniotelic animals are localized in mitochondria (10). In ureotelic animals, arginase is involved in ammonia detoxication in the ornithine-urea cycle and is localized in cytosol. The cytosolic and mitochondrial arginases are isoenzymes named A-I and AII, respectively (11). They are encoded by two separate genes. The arginase gene duplication is relatively recent, and occurred after separation of vertebrates and invertebrates (9). It has been suggested that the mitochondrial A-II is a surviving form of the ancestral arginase, because the cytosolic A-I is restricted to a subset of more recently evolved species (11).

The pattern of occurrence of the arginase isoenzymes implies that the primordial function of the enzyme is regulation of cellular arginine and ornithine metabolism, unrelated to the urea cycle. Ornithine, the product of arginase-catalyzed reaction, is a substrate for synthesis of proline and polyamines. It is important to know that ornithine is formed from glutamate via the pathway leading to arginine synthesis as well. This pathway occurs in bacteria, plants and animals (10). Both in plants and animals, polyamines (putrescine, spermidine, and spermine) are involved in a variety of growth and developmental processes, and they bind directly to DNA and RNA (12). It has been also shown that polyamines play a pivotal role in wound healing. Proline (as hydroxyproline) is indispensable for the collagen biosynthesis in animals and for the synthesis of cell wall proteins in plants. Participation of ornithine in such vital processes suggests that arginase could be regulated by factors influencing development and growth of organisms. TGF- $\beta$ belongs to a superfamily of ancient proteins, known in all bilaterians, members of which play important signaling roles in embryogenesis (13).

\section{TGF- $\beta$ SUPERFAMILY OF PROTEINS}

Transforming growth factor- $\beta$ was originally discovered as a secreted factor that induced malignant transformation in vitro. It is a prototype member of a superfamily of secreted, homodimeric polypeptides. These factors affect a variety of biological processes in both transformed and normal cells, including regulation of embryogenesis, adult cell differentiation, inflammation, and wound repair $(14,15)$.
The TGF- $\beta$ superfamily may be divided into subfamilies according to sequence homology. One subfamily consists of the closely related TGF- $\beta 1,-2$, and -3 . TGF- $\beta 2$ and $-\beta 3$ take part in development signaling, while TGF- $\beta 1$ signals act in inflammatory responses and tissue necrosis (15). TGF- $\beta 1$ cDNAs from different animal species (together with chicken and Xenopus) show an extremely high degree of conservation (14). Fish TGF$\beta$ homologs cluster with their mammalian TGF- $\beta 1,-\beta 2$, and $-\beta 3$ counterparts (15).

Bone morphogenetic proteins were initially characterized as factors that induce bone and cartilage formation $(16,17)$. Bone morphogenetic proteins (BMPs) are critical in development, hematopoiesis, as well as cellular chemotaxis, and cellular differentiation $(18,19)$. In the BMPs subfamily, BMPs- 2 and -4 bear closest homology to the decapentaplegic complex protein, a Drosophila protein mediating dorsal/ventral axis specification (14). BMPs-5, $-6,-7$, and -8 most closely resemble Drosophila protein $60 \mathrm{~A}$, which is required for the growth of imaginal tissues and for patterning of the adult wing (20). Genes encoding members of the bone morphogenetic factor (BMP) protein family have been identified in a sea anemone and an echinoderm (21).

Genes of TGF- $\beta$ superfamily members cluster in two major clades: TGF- $\beta$ sensu stricto/TGF- $\beta$ related (e.g., Activins, Leftys, and GDF8s) ligands and BMP related (e.g., BMPs and Nodals) (22). TGF- $\beta$ sensu stricto ligands have been identified only in deuterostomes (Echinodermata, Hemichordata, and Chordata) and are not present in genomic screens of Caenorhabditis, Drosophila, or Nematostella (23).

Receptors of TGF- $\beta$ pathway are serine threonine kinases categorized as type I and type II $(24,25)$. Vertebrates have seven distinct type I receptors, each of which can mix and match with one of five type II receptors to mediate signals for the TGF- $\beta$ family ligands (26). Ligand binding to the constitutively phosphorylated type II receptors stimulates recruitment of type I receptors and formation of a heterodimeric receptor complex. In the complex, type I receptors are transphosphorylated by type II receptors (13). A signal from type I receptor to the nucleus is channeled into one of two intracellular pathways via Smad family of proteins. Three of the receptors phosphorylate the R-Smads (receptor-regulated Smads); Smad2 and Smad3 and thereby transduce TGF- $\beta$-like signals, whereas the other four receptors activate the R-Smads; Smad1, Smad5, and Smad8 to mediate signals characteristic of those initiated by BMPs (26-28). These R-Smads form multisubunit complexes with a common partner Smads (Co-Smads; Smad4) before entering the nucleus to affect a response (29). Both R-Smads and Co-Smads are found in all metazoans (30). I-Smads; Smad6/7 play inhibitory function, stimulating receptor degradation, or competing with R-Smads in formation of complexes with Smad4 (29, 31). The regulatory activity of I-Smads evolved after divergence of the poriferan lineage (32).

Binding of Smads to DNA is not especially specific; they play a role of comodulators, which act together with transcription factors (pan-metazoan Fos/Jun and Myc), transcription coactivators (pan-metazoan CBP and CBF- $\beta$ ), and transcription corepressors (Ski/Sno) to recruit basal transcription machinery (32). The formation of Smad complexes gives a wide range of cooperative interactions, thus enables TGF- $\beta$ signaling to evoke multiple responses 
ranging from embryonic development to wound repair. ARSmads (activin/TGF- $\beta$-specific R-Smads) transactivate various target genes through interaction with various DNA-binding partners, including plasminogen activator inhibitor-1 (PAI-1), type I collagen, junB, Smad7, and Mix.2. For inhibition of cell growth by TGF- $\beta$, AR-Smads induce the transcription of cyclin-dependent kinase (CDK) inhibitors p21 and p15. In addition, Smad3 binds directly to the promoter region of c-myc and represses the transcription of c-myc. In contrast, only a few target genes for BMPs have been identified, including Id (inhibitor of differentiation or inhibitor of DNA-binding) 1/2/3, Smad6, Vent-2, and Tlx-2. Id proteins, however, play important roles in multiple biological activities of BMPs (27). Id proteins act as negative regulators of cell differentiation and positive regulators of cell proliferation (33).

Ligands, receptors of the TGF- $\beta$ pathway, and Smads are ancient proteins. They emerged already in the metazoan stem lineage. ISmads, multiple ligand traps, and SARA have been added to the signaling pathway after the divergence of sponges (32).

Transforming growth factor- $\beta$ and BMP signaling pathway is evolutionary conserved, as it was shown for worms, flies, and vertebrates [Ref. (26)].

\section{TGF- $\beta$ FUNCTION IN EMBRYOGENESIS AND WOUND HEALING OF INVERTEBRATES}

Caenorhabditis elegans is a free-living nematode, a member of the lineage, which appeared more than 470 million years ago (34). There are at least three distinct TGF- $\beta$-like pathways in this worm (35). One of them controls the body size and morphology of the male tail, but five genes of this pathway (dbl-1, sma-2/-3/-4/-6) contribute to resistance against Pseudomonas aeruginosa infection (36). This pathway controls induction of some genes induced after Serratia marcescens infection, including lys-8 (lysozyme) (37). Moreover, $d p p$, a $d b l-1$ homolog in Drosophila, is up-regulated upon immune challenge $(38,39)$. This pathway shows a clear homology to the mammalian TGF- $\beta$ pathway (40), which plays an important role in immune responses (41). Some targets of this pathway in Caenorhabditis are known: $m a b-21$, involved in male ray pattern formation, and lon-1 and lon-3, involved in regulation of the body size. The latter two encode a cysteine-rich secretory protein and collagen, respectively. The lon-1 and lon-3 are mainly expressed in the hypodermis, as they are essential for the body size regulation $(42,43)$.

This finding implies that the ancestral pathway of TGF- $\beta$ signaling in embryogenesis is bound with immune reactions in the Protostomia, suggesting that TGF- $\beta$ pathway in immunity has been conserved generally across their evolution. Induction of collagen gene in Caenorhabditis during bacterial infection links developmental processes with the tissue repair induced by pathogens. Collagen is needed for extracellular matrix deposition during both embryogenesis and wound repair. Hemocytes must migrate to wounded area for the synthesis of collagen fibrilles. In lesioned leeches (Annelida), immunocytes are the first cells that are also involved in closing the wound by using pseudopodia to bridge the epithelial edges. Subsequently, additional immunocytes complete the obstruction together with granulocytes and NK-like cells (3). Throughout embryogenesis, hemocytes carry out important developmental functions within the embryo, such as the engulfment and removal apoptic cells and the laying down of many extracellular matrix molecules, including collagen IV and laminin, which compose the basement membrane surrounding internal organs [Ref. (44)]. Drosophila hemocytes are similar to leukocytes in respect of activation and migration toward wounds. A requirement for phosphoinositide 3-kinase (PI3K) for the polarization and active hemotaxis of hemocytes toward an epithelial wound shows a striking analogy with the mechanism of cell chemotaxis used by Dictyostelium discoideum, mammalian neutrophils (45), as well as fish macrophages (46). Migration of Drosophila hemocytes toward wounds depends on CDC42 and Rho signal transmission (47) and PI3K signaling (45). The migratory pattern of hemocytes in Drosophila embryos is independent of PI3K signaling, but depends on chemotactic signals from the PDGF/VEGF ligands (45).

During wound healing in the snails Lymnaea stagnalis (48) and Limax maximus (49), hemocytes exhibit fibroblast activity while secreting the extracellular matrix. Similar transformation of a cell type was observed in fibroblasts transformed into myofibroblasts at injured sites when acting in wound contraction (50). It points to the role of hemocytes in invertebrate tissue repair, similarly to the mammalian wound models, in which the macrophages are essential cells participating in wound healing (51). PDGF-AB (hetrodimer) and TGF- $\beta 1$ stimulate chemotaxis of different cell types, especially hemocytes (49). The increased number of hemocytes contribute to earlier wound closure at the injured site. The removal of damaged tissue residues is also accelerated by stimulation of the phagocytic activity of recruited hemocytes. TGF- $\beta 1$ regulates expression of genes of collagen type I and III, and fibronectin $(52,53)$. This may mean that the mechanism of wound healing is conserved from invertebrates to mammals what's more, arginase gene expression has been documented in hemocytes (54).

Tissue injury in humans triggers migration of macrophages, platelets, fibroblasts, myofibroblasts, and eosinophils releasing TGF- $\beta$. TGF- $\beta$ stimulates fibroblasts and other reparative cells to proliferate and synthesize extracellular matrix components (elastin fibers, collagen fibrils, protein-polysaccharides, and glycoproteins). This leads to a provisional repair, followed by fibrosis and ultimately scarring. Fibrosis of many organs (liver, heart, kidney, pancreas, and skin) is mediated by TGF- $\beta$ [Ref. (55)]. In experimental murine Schistosoma mansoni infection, gene expression of type I and type III interstitial collagens, basement membrane collagen, and TGF- $\beta 1$ show increased levels of expression after primary infection (56). Transcription of type I procollagen chains pro 1 and pro 2 is TGF- $\beta$-regulated through two different pathways during tissue fibrosis. Expression of pro 1 depends on the TGF- $\beta$ activator protein and expression of pro $\alpha 2$ depends on Smad signaling of TGF- $\beta$ pathway. In addition, there are other cellular factors and DNA-binding elements required for the transcription of these type I procollagen genes. New synthesized procollagen molecules are processed by enzymes outside the cell.

In the evolution of nematodes, they changed their original freeliving habitus to commensal one and finally to parasitize tissues of animals (57). The evolution of plathelminths was different. They changed ectoparasitic mode of life of monogenean trematodes to endoparasitic one of digeneans and tapeworms. Invertebrates that are parasitized by these worms, heal damages to the tissue due 
to activation of polyamine and collagen synthesis. Thus arginase induction required for wound healing in animals without acquired immunity could be based on the TGF- $\beta$ signaling pathway.

Aside being a substrate for proline synthesis pathway, ornithine is a substrate for polyamine production in all eukaryotic cells. As polyamines are required for high rates of protein synthesis and cell proliferation (58), they play a pivotal role in repair processes. Stimulation of putrescine synthesis was observed during regeneration of earthworms and planarians (59). Regenerating tissues produce spermine, and injured or dying cells release spermine into the extracellular milieu, so that tissue levels of this compound increase significantly at inflammatory sites of infection or injury (60). In snails resistant to the Schistosoma mansoni infection (61), increased gene expression of ornithine decarboxylase in hemocytes points to the enhancement of arginase activity, which results in ornithine production $(62,63)$. Ornithine decarboxylase produces putrescine used for the synthesis of other polyamines involved in DNA protection during cell proliferation. Polyamines assist in wound healing following miracidial penetration.

Mollusks can be infected with viruses, bacteria, fungi, protists, digenean trematodes, polychetes, and copepods (64). The infective stage of the protozoan (haplosporidian) Haplosporidium nelsoni invades the bivalve tissues through gills and palps spreading then through the body. Infection of the bivalve Crassostrea virginica with this protist leads to an increase in the number of circulating hemocytes and their infiltration into tissues (65). It is suggested that these cells are involved in limiting parasite damage by plugging lesions, removing debris, and repairing damaged tissue.

In hemocytes of the snail Biophalaria glabrata infected with the digenean trematode Schistosoma mansoni, for which a definitive host is human, the expression of TGF- $\beta$ receptor gene was slightly lowered in comparison with those of resistant strains. Early gene expression was measured only $2 \mathrm{~h}$ post exposure to miracidia (61).

Transforming growth factor- $\beta$ signaling is essential for extracellular matrix development in cold-blooded animals (66). As a result of infection of salmonid fish with the ectoparasitic caligid crustacean Lepeophtheirus salmonis insufficient expression of several regulatory proteins, among them TGF- $\beta$, brought up delayed expression of collagen $2 \mathrm{a}$ and delayed wound healing. Arginase gene expression was markedly increased in intact skin of infected fish (67). Support for the hypothesis that arginase expression is related to collagen expression comes from observations that arginase trancripts are down-regulated in concert with collagen a in resistant oysters five days after challenge with the gramnegative bacterium Roseovarius crassostreae (68). This extracellular pathogen colonizes the oyster's inner shell surface and causes lesions in the epithelial mantle.

Efficient wound healing in invertebrates based on induction of genes for arginase and collagen biosynthesis (68) mediated by $\operatorname{TGF} \beta(49,65)$, but without cytokines of Th2 cluster being involved, may mean that also in vertebrates such mechanism of healing is possible. An innate response to injury may occur in absence of any adaptive response and can be triggered solely by tissue injury (69). Although IL-4/IL-13 mediated responses may be important in tissue repair, they do not appear to be essential, as the incision is effectively healed in the mice that lack IL- 4 or IL- 4 receptor. Nonetheless, the importance of type 2 cytokines in damage tissue remodeling and fibrosis is well documented (70). Possibly IL-4 and/or IL-13 mediate a more rapid form of tissue repair that it is necessary just to maintain tissue integrity. According to Allen and Wynn (71), Th2 immunity in vertebrates evolved as a means to rapid tissue damage repair caused by metazoan invaders rather than just to control parasite numbers.

\section{M2-TYPE OF MACROPHAGE RESPONSE WITHOUT HELP OF Th2 CYTOKINES}

Transforming growth factor- $\beta$, IL-4, and IL-13 are key cytokines skewing macrophages to the M2-type response that is typical for allergy and metazoan parasite infection. Arginase induction is the hallmark of this response. This raises the question whether M2-type of macrophage response could be induced solely by multicellular parasites without help of Th2 cytokines.

A strong wound healing response would occur in helminth infection, as tissue migratory or tissue invasive parasites often lead to physical trauma. A Th2-type protective immune response develops following infection with many tissue-dwelling intestinal nematode parasites (Heligmosomoides polygyrus, Trichuris muris, or Trichinella spiralis) or trematodes and is characterized by elevations in IL- 4 and IL-13 and increased numbers of CD4 ${ }^{+}$T cells, granulocytes, and macrophages. These cells accumulate at the site of infection and may mediate resistance to worms $(72,73)$. This is a kind of defense strategy of the host, but it eventually favors a survival of parasite.

Excretory-secretory (ES) products or parasite enzymes activate and regulate host-immune response at the macrophage level through inhibition of pro-inflammatory cytokines production and induction of macrophages toward the M2-type of activation.

Trichinella spiralis is the parasitic nematode of higher vertebrates, which causes pathological changes in various tissues of the host. Binding of TGF- $\beta$ with specific antibodies abrogated effect of infection on arginase activity in guinea pig alveolar macrophages (74). ES products from Trichinella spiralis raise the expression of interleukin-10, TGF- $\beta$, and arginase-1 in J774 A.1 macrophages in the absence of Th2 cytokines (75). In addition, ES products significantly inhibit translocation of NF- $\kappa \mathrm{B}$ into the nucleus and the phosphorylation of both ERK1/2- and p38MAP-kinases in J774A.1 macrophages stimulated with lipopolysaccharide (LPS) (an antigen of Gram-negative bacteria). Treatment of peritoneal macrophages with a recombinant of $53-\mathrm{kDa}$ protein derived from T. spiralis brought about expression of mannose receptor, a novel mammalian lectin (Ym1), arginase-1, and IL-10, hallmarks of M2 phenotype. This effect was independent of IL-4R $\alpha$, but dependent on STAT6 (76).

Infections with the trematodes Fasciola hepatica or Schistosoma mansoni cause destruction of the host liver tissues, damage to bile ducts, atrophy of the portal vessels, and secondary pathological conditions. Secreted peroxiredoxins may induce alternative activation of macrophages. They stimulate $\mathrm{Ym} 1$ expression in vitro, which shows their action independent of IL-4/IL-13 signaling (77). As expected, administration of recombinat peroxiredoxins from these trematodes to the wild type and IL- $4^{-} /^{-}$and IL- $13^{-} /^{-}$mice induces alternatively activated macrophages. Also eggs of $S$. mansoni laid in the smallest blood vessels cause tissue reaction in the form of inflammation, necrosis, connective tissue encapsulation, 
and eventual scar formation during their migration through the tissue to the colon. The eggs trapped in the liver induce fibrosis and are associated with production of proline (78). The immunomodulatory pentasaccharide LNFPIII, which contains the Lewis $\mathrm{X}$ trisaccharide, is a component of schistosome soluble egg antigen. It up-regulates expression and activity of arginase-1, as well as expression of $\mathrm{Ym} 1$ in macrophages (79) but does not induce expression of FIZZ-1, MGL-1, or MMR. Upregulation of arginase I and Ym1 is independent of IL-4 and IL-13. Binding of LNFPIII to C-type lectins on the surface of macrophages leads to alternative nuclear factor (NF) $-\kappa \mathrm{B}$ activation (80) and may induce arginase-1 and Ym1 directly without IL-4 and IL-13. An injection of LNFPIII initiates alternative activation, do not mimicking complete infection because it does not cause FIZZ-1 expression, besides upregulation of Ym1. Interestingly, Loke et al. (69) have found that surgical trauma leads to elevation of markers of alternative activation without presence of $T$ cells. However, the innate expression of Ym1, FIZZ-1, and arginase-1 requires either IL-4 or IL-13. Expression of arginase-1 occurred early in response to surgery. It increases with growing up to third day post surgery and then returns to baseline by 1 week, but is sustained only in the parasite-implanted animals.

Protozoan parasite Toxoplasma type I and type III strains may induce the M2 phenotype, while the type II strain induces M1 phenotype (81). The alternative activation of macrophages is dependent in large part on the Toxoplasma polymorphic protein kinase ROP16, while the classical activation of macrophages by the type II strain is due to unique ability of its GRA15 protein to activate NF- $\kappa$ B pathway and elicit pro-inflammatory cytokines. Both enzymes seem act in a way specific to the host. According to authors, parasite effectors from different Toxoplasma strains evolved to work optimally in hosts predisposed to certain types of immune responses, such as those along the Th1/Th2/Th17 or M1/M2 axes. Ending up to the wrong host might lead to severe disease and failure to establish chronic infection.

\section{MACROPHAGE POLARIZATION BY TGF- $\beta$ SUPERFAMILY PROTEINS}

In the adult Drosophila immune response, Dpp (decapentaplegic), a BMP-type signal, is rapidly activated by wounds and represses the production of antimicrobial peptides. The activin/TGF- $\beta$-like signal dawdle (daw), in contrast, is activated by Gram-positive bacterial infection but repressed by Gram-negative infection or wounding; its role is to limit infection-induced melanization. Genes $d p p$ and daw are expressed in hemocytes but also in other tissues. The hemocyte population in the adult fly is comprised of subsets of cell that can be defined through distinct gene expression profile. According to Clark et al. (82), it is likely that expression of $d p p$ and $d a w$ by a subset or subsets of phagocytes indicates distinct immunomodulatory functions by these cells. Both $d p p$ and daw inhibit immune responses. This makes the fly similar to mammals, in which both activin and TGF- $\beta$-like and BMP-like signals are largely anti-inflammatory $(83,84)$, in contrast with the nematode Caenorhabditis, where the TGF- $\beta$ superfamily member $d b l-1$ analog of $d p p$ promotes a variety of antimicrobial responses (85).

Both anti- and pro-inflammatory response due to activation of TGF- $\beta$ superfamily receptors by their ligands, TGF- $\beta$, bone morphogenetic protein-7 (BMP-7), BMP-6 have been found in macrophages of rodents. Surprisingly few studies have evaluated the effect of TGF- $\beta$ signaling on macrophages. Mouse macrophages lacking T $\beta$ RII (transforming growth factor- $\beta$ receptor II) are defective in expression of genes that characterize the M2-type of activation, suggesting that TGF- $\beta$ signaling is needed for the alternative activation of macrophages. Lack of $T \beta R I I^{-1-}$ is associated with basal expression of arginase-1 (protein and mRNA) significantly decreased in comparison with the wild type both in naïve peritoneal macrophages and bone marrow-derived macrophages, BMDM, (86). Moreover, when $T \beta R I I^{-1-} \mathrm{BMD}$ macrophages are polarized toward an M2 phenotype with IL-4, induction of Arg-1 is very low. Expression of Arg-1 is increased in $W T$ macrophages stimulated with TGF- $\beta 1$. As transcription of other M2 markers including $y m 1$ ceases in $T \beta R I I^{-/-}$BMDMs, apparently signals through T $\beta$ RII modulate the M2 transcription program. TGF- $\beta$ contributes to M2 polarization of macrophages with IL-4 through co-signaling to Akt, which is one of the TGF- $\beta 1$ non-Smad-associated signal transduction pathways in other cell types (87).

Bone morphogenetic protein-7 activates receptor BMPR2 in monocytes, which results in phosphorylation of RSMAD1/5/8/and activation of down-stream mediators in the Smad pathway. It plays a role in polarization also in M2 macrophages, as manifested by increased expression of antiinflammatory cytokines (88). In bone marrow-derived M2 macrophages, increased polarization results from activation of PI3K pathway (89). Activation of the PI3K pathway controls production of transcription factors. They regulate key inflammatory cytokines resulting in increased expression of anti-inflammatory markers (90). Arginase- 1 and IL-10 level is significantly increased following treatment of monocytes with BMP-7 (88). In addition to the canonical Smad-dependent pathway for TGF- $\beta$ signaling, a Smad-independent pathway, namely the mitogen-activated protein kinase (MAPK) pathway (p38MAPK and JNK) may act (91). Activation of the NF- $\kappa$ B pathway via the X-linked inhibitor of apoptosis (XIAP) transduces BMP signaling (92). Different to BMP-7, BMP-6 may induce pro-inflammatory inducible NOS (iNOS) and TNF- $\alpha$ in peritoneal macrophages (93). The general phenotype of macrophages in response to BMP- 6 is similar to that of macrophages exposed to LPS (94). BMP-6 in macrophages appears to counteract TGF- $\beta$. It is likely that the BMP- 6 induction of expression of inducible NO synthase occurs through IL-1 $\beta$ via Smad and NF-kappaB signaling pathways (95). IL-1 $\beta$, in turn, up-regulates iNOS expression via the NF-кB pathway. However, the possibility that BMP- 6 may directly activate NF- $\kappa$ B signaling could not be excluded because TGF- $\beta$ activates kinase 1 (TAK1), which is a component of the BMP signaling pathway in Xenopus and mouse embryonic development $(96,97)$. TAK1 and its regulators (TAB1 and TAB2) form complexes and activate the IKK complex (98). The latter possibility suggest that pathway used in embryonic signaling could be used in innate immunity response to induce NO production. Interestingly, $\mathrm{NO}$ and ornithine (the product of arginase described earlier), both originate from the same amino acid, arginine, via different enzymatic reactions, which were called figuratively "The arginine fork in the road" (99). 


\section{EVOLUTION OF NITRIC OXIDE SYNTHASE}

In macrophages, $\mathrm{NO}$ is a crucial mediator of cytotoxicity. It has been shown to have microbicidal, antiviral, antiparasitic, and antitumor effects. NO production is usually mediated by nitric oxide synthase (NOS) (EC 1.14.13.39). To date, three isoforms of NOS have been characterized: iNOS, neuronal NOS (nNOS), and endothelial NOS (eNOS). In macrophages, iNOS is transcriptionally induced in response to LPS, TNF- $\alpha$, interferon- $\gamma$ (IFN- $\gamma$ ), and interleukin-1 $\beta$ (IL-1 $\beta$ ) (100). The signaling pathway for iNOS expression in macrophages involves NF- $\kappa \mathrm{B}$ and signal transducer and activator of transcription (STAT).

Three NOS isoforms originally described in mammalian tissues $(100,101)$ are encoded by distinct genes: for eNOS, nNOS, and iNOS. All they share much of their sequence with cytochrome $\mathrm{P} 450$ reductase in their $\mathrm{C}$-terminal reductase domains and have a common oxygenase domain.

The interdomain linker between the oxygenase and reductase domains contains a calmodulin-binding sequence. In eNOS and nNOS, physiological concentrations of $\mathrm{Ca}^{+2}$ in cells regulate the binding of calmodulin to the linker, thereby initiating electron transfer from the flavins to the heme moieties. In contrast, calmodulin remains tightly bound to the iNOS $\left(\mathrm{Ca}^{+2}\right.$-insensitive isoform). Expression of iNOS is strongly activated in the presence of LPSs or in response to potentially damaging stimuli, resulting in a high and long-term NO yield. iNOS is primarily involved in defense reactions and cytotoxicity.

Nitric oxide synthase ancestry goes back to early bacteria from before a couple billion years ago. In all prokaryotic enzymes only the oxygenase domain is found $(102,103)$. In NOS evolution, multiple events of gene loss and gain in various lineages occurred.

Nitric oxide synthase occurs probably in almost all invertebrates ranging from jellyfish (104) and hydra (105) to fly (106) and parasitic worms (107), as well as mollusks and arthropods (108). NOS enzymes from insects (109-111) and mollusks [(112), Ref. (113)] have greater overall sequence similarity to a neuronal-like NOS than to iNOS or eNOS in vertebrates. However, cnidarian (Discosoma) and slime mold (Physarum) NOSs $(113,114)$ lack the distinct structural element that is present as an insertion in the reductase domains of constitutive NOSs but is absent in iNOSs of vertebrates. This insert is thought to be an autoinhibitory loop, which impedes binding of $\mathrm{Ca}^{2+}$ to calmodulin and enzymatic activation. This insert reduces potentially toxic NO yields following the activation of iNOS. Since the Discosoma NOS is structurally similar both to the only known non-animal conventional NOS and to vertebrate iNOS isoforms, the inducible type of the enzyme may be ancestral for animal NOSs. In contrast to vertebrate species, which have three NOS genes, only one type of NOS isoform has been found in the genomes from insects and tunicates. Mollusks, sea urchins, and cephalochordates have at least two NOS genes but no NOS genes have been identified in Caenorhabditis elegans. These findings imply that more than one NOS co-existed in the common ancestor of all animals and it was lost in some animal lineages in the course of evolution. On the other hand, in some groups, such as mollusks (with at least two different types of NOS) and chordates (2-3 NOS genes), duplication events for NOS genes may have occurred more than once. Moreover, duplications happened independently in the evolution of inducible type NOS, since some fishes have more than one iNOS-like gene (113). The diversification of vertebrate NOSs occurred in parallel in many lineages, which cluster into three distinct groups corresponding to the mammalian iNOS, eNOS, and nNOS, iNOS probably being most basal. eNOS apparently originated as the last, within the mammalian clade.

The primary and evolutionary conservative role of $\mathrm{NO}$ is NO-cGMP signaling, acting in many different invertebrates from sponges, insects, and mollusks to cephalopods [Ref. (115)]. A defense function of NO was observed in the crustacean (116), and mollusk hemocytes [Ref. (117)]. In general, defense functions in invertebrates are accomplished by superoxide produced by phagocyte NADPH oxidase (which appeared before the divergence of the Choanoflagellata and metazoans), antimicrobial peptides, lysozymes, hemolymph clotting, and melanization [Ref. (115)]. This suggests that the function of arginase as the key enzyme producing ornithine in metazoans, indispensible for tissue repair, is more ancient than the cytotoxic activity of free radical NO, the product of NOS. One may conclude that the wound healing function of M2 macrophages is more deeply rooted in history of life than the cytotoxic activity of M1 macrophages.

\section{REGULATION OF NITRIC OXIDE PRODUCTION IN INSECTS AND MICE}

Most of research on the NOS refers to three animal species: fruit flies Drosophila melanogaster, mice Mus musculus, and humans Homo sapiens. Presumably, the insects are the least advanced its evolution. Mice, as rodents, are relatively primitive mammals, closest relatives of the order Primates, to which humans belong. From evolutionary point of view, the rodent macrophages, commonly used as a model for immunological investigations, better suit to studies on innate immunity reactions in vertebrates than human ones.

The model for studying arthropod immunity is the antimicrobial defense in Drosophila. IMD pathway performs a signaling function by inducing host defenses in response to Gram-negative bacteria. Activation the IMD signaling pathway leads to the activation of NF- $\kappa \mathrm{B}$ homolog Relish and production of antimicrobial peptides $(118,119)$. The cells in Drosophila gut detect the pathogen and activate hemocytes via an NO-dependent signal. The hemocytes act in turn to activate immune-inducible gene expression in the fat body (the insect liver analog) by an as-yet-unknown signal (118). In Anopheles stephensi, expression of immune responsive genes, including NOS, is up-regulated in response to the presence of Plasmodium parasites in the midgut (120).

It has been found that $A$. stephensi NOS possesses a putative LPS- and cytokine-responsive transcription factor binding site (121). Invertebrates have cytokine-like proteins similar to the interleukins and tumor necrosis factors of vertebrates (122). Transcription factor binding sites in the $5^{\prime}$-flanking sequence demonstrate a bipartite distribution of LPS- and inflammatory cytokine-responsive elements that are strikingly similar to that described for murine iNOS gene promoters $(123,124)$. Studies of Drosophila NOS regulation have shown (125) that insect NOS activity is solely dependent on $\mathrm{Ca}^{2+}$ and calmodulin, like the constitutive vertebrate NOSs. Although the activity of Drosophila NOS 
is very low compared to other NOSs, low amount of NO produced may be sufficient for functioning as a signaling molecule (126).

As already commented, NO is rather a signaling than cytotoxic molecule in invertebrates. In vertebrates, as exemplified by rodent macrophages, high amounts of NO are produced as a result of activation of iNOS with LPS and IFN $\gamma$. This is a part of defense armor, which otherwise acts as a double edge sword. However, stimulation of macrophages only with LPS results in a low NO production and less than $15 \%$ of cells is iNOS positive. IFN $\gamma$ enhanced LPS-induced secretion of NO by recruiting increasingly greater numbers of macrophages into the production of iNOS (127). The gene of iNOS is synergistically activated by LPS and IFN $\gamma(123,124)$. The iNOS promotor contains two important regions termed RI and RII. The effects of LPS stimulation are mediated by elements in both RI and RII, whereas IFN $\gamma$ functions through RII only $(123,124)$. In addition, IFN $\gamma$ alone is not able to activate through RII, acting solely to augment the effect of LPS on RI (123). A variety of LPS response elements, including NF- $\kappa B$, occurs and the NF- $\kappa \mathrm{B}$ site in LPS-mediated transcriptional activation of iNOS is required (128). Perhaps the increase of frequency of LPS responsive cells in effect of IFN $\gamma$ action, and consequent $\mathrm{NO}$ production is the key factor to enhance NO formation. It leads to $\mathrm{M} 1$ type of response.

TGF- $\beta 1$ seems to be the most potent regulator of iNOS. In natural killer cells, neutrophils and macrophages, TGF- $\beta 1$ diminishes iNOS activity, influencing gene expression, mRNA stability and translation, and NOS protein stability (129). For suppression of LPS-stimulated iNOS in bone marrow-derived mouse macrophages, both Smad2 and Smad3 are required. Down regulation of iNOS mRNA undergoes by suppressing the IRF3- IFN $\beta$ STAT1 pathway (130). Mutual feedback regulation between iNOS and TGF- $\beta 1$ is also possible, as latent TGF- $\beta 1$ can be activated by exogenous NO (131).TGF- $\beta$ appears to be important endogenous mediator that keeps resident/wound healing macrophages in M2 dominant mode. A decrease in TGF- $\beta$ production in macrophages brought about "activation" of these cells. Similarly, removing of TGF- $\beta$ from cell culture (coming from serum added), caused much more NO produced, and less synergy between LPS and IFN- $\gamma$ in stimulation of NO production (1).

\section{CONCLUDING REMARKS}

Sophisticated ways of signaling observed in contemporary vertebrates show how complex are results of molecular evolution. Although specialization of macrophage responses is based on two ancient mechanisms: cytotoxic activity of iNOS and anabolic function of arginase (Figure 1). It is suggested here that not defense against infection but rather the TGF- $\beta$-signaling was at the origin of the M1/M2 macrophage specialized functions. Such signaling is known to operate already in primitive invertebrates, both in their embryonic development and wound healing. A prototypic inducer of M1 response bacterial LPS, alone activates production of only a small amount of NO by iNOS-type enzyme and generates signal propagation through cGMP cyclase in invertebrates. It remains unknown, to what degree invertebrate analogs of IFN $\gamma$ would be able to enhance LPS-induced NO production, as no experimental data about enhancement of NO production by IFN $\gamma$-like cytokine in Drosophila are available. Presumably, the ability of M1 macrophages to produce large amounts of NO in response to microbial infection is a vertebrate evolutionary invention, known to be present already at the fish grade (132). At this stage the arginase function in M2 macrophages, inherited after invertebrate ancestors, was to deliver ornithine for processes of extracellular matrix synthesis, of importance in organogenesis and wound healing. The latter serves also as a protection against metazoan parasites. Thus, the main function of M2 macrophages is originally connected with the TGF- $\beta$

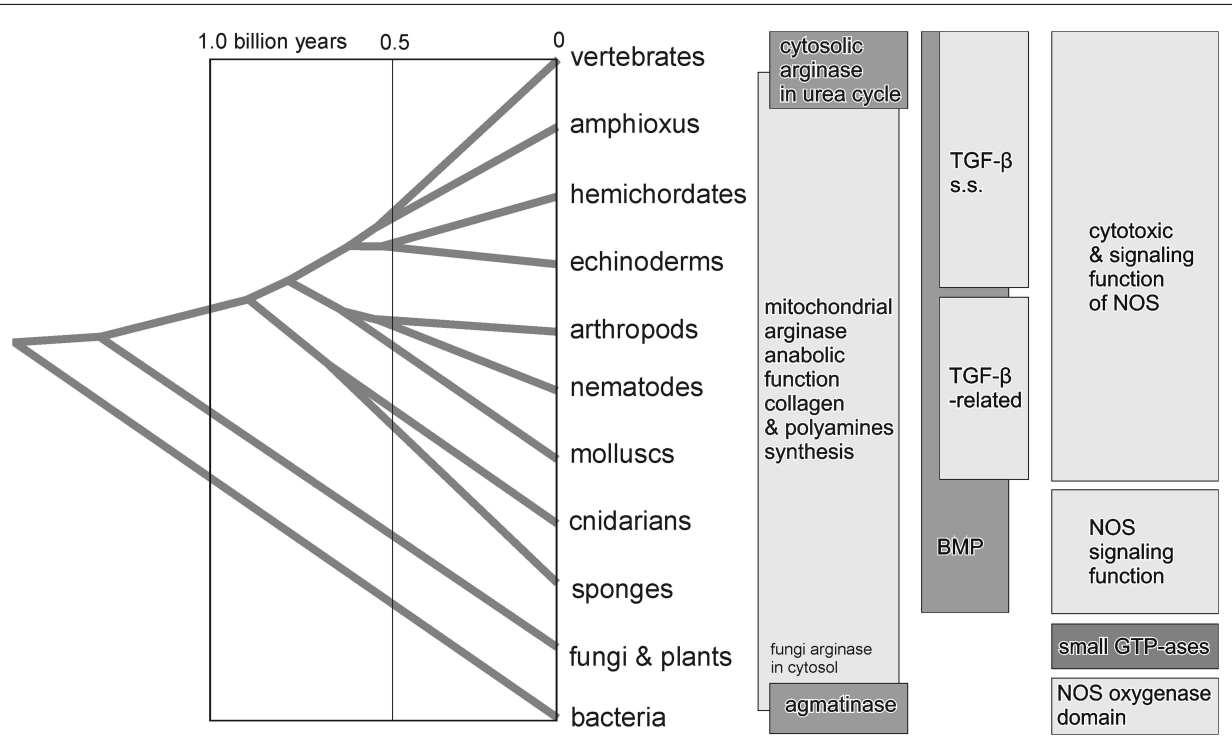

FIGURE 1 | Proposed order of appearance of arginase, TGF- $\beta$ superfamily of proteins, and nitric oxide synthase (NOS), superimposed on the metazoan phylogenetic tree, implies a pattern of polarization of vertebrate macrophage to M1 and M2-types of activation. 
superfamily of proteins, which in primitive metazoans are involved in regulation of tissue and organ differentiation in embryogenesis. Looking back in evolution also indicates that both NOS/NO and arginases/ornithine are primitive innate responses in macrophages that long preceded the development of $\mathrm{T}$ and $\mathrm{B}$ cells (adaptive immunity).

\section{REFERENCES}

1. Mills CD, Kincaid K, Alt JM, Heilman MJ, Hill AM. M-1/M-2 macrophages and the Th1/Th2 paradigm. J Immunol (2000) 164:6166-73. doi:10.4049/ jimmunol.164.12.6166

2. Mosser DM. The many faces of macrophage activation. J Leukoc Biol (2003) 73:209-12. doi:10.1189/jlb.0602325

3. Ottaviani E. Immunocyte: the invertebrate counterpart of the vertebrate macrophage. Inv Surv J (2011) 8:1-4.

4. Mosser DM, Edwards JP. Exploring the full spectrum of macrophage activation. Nat Rev Immunol (2008) 8:958-69. doi:10.1038/nri2448

5. Mylonas KJ, Nair MG, Prieto-Lafuente L, Paape D, Allen JE. Alternatively activated macrophages elicited by helminth infection can be reprogrammed to enable microbial killing. J Immunol (2009) 182:3084-94. doi:10.4049/ jimmunol.0803463

6. Hesse M, Modolell M, La Flamme AC, Schito M, Fuentes JM, Cheever $\mathrm{AW}$, et al. Differential regulation of nitric oxide synthase-2 and arginase1 by type 1/type 2 cytokines in vivo: granulomatous pathology is shaped by the pattern of L-arginine metabolism. J Immunol (2001) 167:6533-44. doi:10.4049/jimmunol.167.11.6533

7. Chen H, McCaig BC, Melotto M, He SY, Howe GA. Regulation of plant arginase by wounding, jasmonate, and the phytotoxin coronatine. J Biol Chem (2004) 279:45998-6007. doi:10.1074/jbc.M407151200

8. Sekowska A, Danchin A, Risler JL. Phylogeny of related functions: the case of polyamine biosynthetic enzymes. Microbiology (2000) 146:1815-28.

9. Samson ML. Drosophila arginase is produced from a nonvital gene that contains the elav locus within its third intron. J Biol Chem (2000) 275:31107-14. doi:10.1074/jbc.M001346200

10. Morris SM. Regulation of enzymes of the urea cycle and arginine metabolism. Annu Rev Nutr (2002) 22:87-105. doi:10.1146/annurev.nutr.22.1 10801.140547

11. Jenkinson CP, Grody WW, Cederbaum SD. Comparative properties of arginases. Comp Biochem Physiol (1996) 114B:107-32. doi:10.1016/03050491(95)02138-8

12. Romero-Calderon R, Krantz DE. Transport of polyamines in Drosophila S2 cells: kinetics, pharmacology and dependence on the plasma membrane proton gradient. Biochem J (2006) 393:583-9. doi:10.1042/BJ20050981

13. Massagué J. TGF- $\beta$ signal transduction. Annu Rev Biochem (1998) 67:753-91. doi:10.1146/annurev.biochem.67.1.753

14. Gitelman SE, Derynck R. Transforming growth factor- $\beta$. In: Nicola NA, editor. Guidebook to Cytokines and their Receptors. Oxford: A Sambrook and Tooze Publication at Oxford University Press (1994). p. 223-6.

15. Magor BG, Magor KE. Evolution of effectors and receptors of innate immunity. Dev Comp Immunol (2001) 25:651-82. doi:10.1016/S0145-305X(01)00029-5

16. Wang EA, Rosen V, Cordes P, Hewick RM, Kriz MJ, Luxenberg DP, et al. Purification and characterization of other distinct bone-inducing factors. Proc Natl Acad Sci U S A (1988) 85:9484-8. doi:10.1073/pnas.85.24.9484

17. Wozney JM, Rosen V, Celeste AJ, Mitsock LM, Whitters MJ, Kriz RW, et al. Novel regulators of bone formation: molecular clones and activities. Science (1988) 242:1528-34. doi:10.1126/science.3201241

18. Hogan BL. Bone morphogenetic proteins: multifunctional regulators of vertebrate development. Genes Dev (1996) 10:1580-94. doi:10.1101/gad.10.13.1580

19. Zhao GQ. Consequences of knocking out BMP signaling in the mouse. Genesis (2003) 35:43-56. doi:10.1002/gene.10167

20. Khalsa O, Yoon JW, Torres-Schumann S, Wharton KA. TGF- $\beta$ /BMP superfamily members, Gbb-60A and Dpp, cooperate to provide pattern information and establish cell identity in the Drosophila wing. Development (1998) 125: 2723-34.

21. Lelong C, Mathieu M, Favrel P. Identification of new bone morphogenetic protein-related members in invertebrates. Biochimie (2001) 83:423-6. doi:10. 1016/S0300-9084(01)01260-3
22. Matus DQ, Magie CR, Pang K, Martindale MQ, Thomsen GH. The Hedgehog gene family of the cnidarian, Nematostella vectensis, and implications for understanding metazoan Hedgehog pathway evolution. Dev Biol (2008) 313:501-18. doi:10.1016/j.ydbio.2007.09.032

23. Matus DQ, Thomsen GH, Martin dale MQ. Dorso/ventral genes are asymmetrically expressed and involved in germ-layer demarcation during cnidarian gastrulation. Curr Biol (2006) 16:499-505. doi:10.1016/j.cub.2006. 01.052

24. Wrana JL, Attisano L, Wieser R, Ventura F, Massagué J. Mechanism of activation of the TGF-beta receptor. Nature (1994) 370:341-7. doi:10.1038/370341a0

25. Heldin CH, Miyazono K, ten Dijke P. TGF- $\beta$ signalling from cell membrane to nucleus through SMAD proteins. Nature (1997) 390:465-71. doi:10.1038/ 37284

26. Attisano L, Wrana JL. Signal transduction by the TGF- $\beta$ superfamily. Science (2002) 296:1646-7. doi:10.1126/science.1071809

27. Miyazawa K, Shinozaki M, Hara T, Furuya T, Miyazono K. Two major Smad pathways in TGF- $\beta$ superfamily signalling. Genes Cells (2002) 7:1191-204. doi:10.1046/j.1365-2443.2002.00599.x

28. Qin BY, Chacko BM, Lam SS, de Caestecker MP, Correia JJ, Lin K. Structural basis of Smadl activation by receptor kinase phosphorylation. Mol Cell (2001) 8:303-12. doi:10.1016/S1097-2765(01)00417-8

29. Massagué J, Seoane J, Wotton D. Smad transcription factors. Genes Dev (2005) 19:2783-810. doi:10.1101/gad.1350705

30. Srivastava M, Simakov O, Chapman J, Fahey B, Gauthier ME, Mitros T, et al. The Amphimedon queenslandica genome and the evolution of animal complexity. Nature (2010) 466:720-6. doi:10.1038/nature09201

31. Hanyu A, Ishidou Y, Ebisawa T, Shimanuki T, Imamura T, Miyazono K. The $\mathrm{N}$ domain of Smad7 is essential for specific inhibition of transforming growth factor- $\beta$ signaling. J Cell Biol (2001) 155:1017-27. doi:10.1083/jcb.200106023

32. Richards GS, Degnan BM. The dawn of developmental signaling in the metazoa. Cold Spring Harb Symp Quant Biol (2009) 74:81-90. doi:10.1101/sqb.2009. 74.028

33. Yokota Y, Mori S. Role of Id family proteins in growth control. J Cell Physiol (2002) 190:21-8. doi:10.1002/jcp.10042

34. Balinski A, Sun Y, Dzik J. Traces of marine nematodes from 470 million years old early Ordovician rocks in China. Nematology (2013) 15:567-74. doi:10.1163/15685411-00002702

35. Schulenburg H, Kurz CL, Ewbank JJ. Evolution of the innate immune system: the worm perspective. Immunol Rev (2004) 198:36-58. doi:10.1111/j.01052896.2004.0125.x

36. Tan MW. Genetic and genomic dissection of host-pathogen interactions using a P. aeruginosa-C. elegans pathogenesis model. Pediatr Pulmonol (2001) 32:96-7.

37. Mochii M, Yoshida S, Morita K, Kohara Y, Ueno N. Identification of transforming growth factor- $\beta$ regulated genes in Caenorhabditis elegans by differential hybridization of arrayed cDNAs. Proc Natl Acad Sci U S A (1999) 96:15020-5. doi:10.1073/pnas.96.26.15020

38. Irving P, Troxler L, Heuer TS, Belvin M, Kopczynski C, Reichhart JM, et al. A genome-wide analysis of immune responses in Drosophila. Proc Natl Acad Sci U S A (2001) 98:15119-24. doi:10.1073/pnas.261573998

39. De Gregorio E, Spellman PT, Rubin GM, Lemaitre B. Genome-wide analysis of the Drosophila immune response by using oligonucleotide microarrays. Proc Natl Acad Sci U S A (2001) 98:12590-5. doi:10.1073/pnas.221458698

40. Newfeld SJ, Wisotzkey RG, Kumar S. Molecular evolution of a developmental pathway: phylogenetic analyses of transforming growth factor-b family ligands, receptors and Smad signal transducers. Genetics (1999) 152:783-95.

41. Letterio JJ, Roberts AB. Regulation of immune responses by TGF- $\beta$. Annu Rev Immunol (1998) 16:137-61. doi:10.1146/annurev.immunol.16.1.137

42. Morita K, Flemming AJ, Sugihara Y, Mochii M, Suzuki Y, Yoshida S, et al. A Caenorhabditis elegans TGF- $\beta$, DBL-1, controls the expression of LON-1, a PR-related protein, that regulates polyploidization and body length. EMBO J (2002) 21:1063-73. doi:10.1093/emboj/21.5.1063

43. Maduzia LL, Gumienny TL, Zimmerman CM, Wang H, Shetgiri P, Krishna $S$, et al. lon-1 regulates Caenorhabditis elegans body size downstream of the dbl-1TGF- $\beta$ signaling pathway. Dev Biol (2002) 246:418-28. doi:10.1006/dbio. 2002.0662

44. Fessler JH, Fessler LI. Drosophila extracellular matrix. Annu Rev Cell Biol (1989) 5:309-39. doi:10.1146/annurev.cellbio.5.1.309 
45. Wood W, Faria C, Jacinto A. Distinct mechanisms regulate hemocyte chemotaxis during development and wound healing in Drosophila melanogaster. J Cell Biol (2006) 173:405-16. doi:10.1083/jcb.200508161

46. Grabher C, Cliffe A, Miura K, Hayflick J, Pepperkok R, Rørth P, et al. Birth and life of tissue macrophages and their migration in embryogenesis and inflammation in medaka. J Leukoc Biol (2007) 81:263-71. doi:10.1189/jlb. 0806526

47. Stramer B, Wood W, Galko MJ, Redd MJ, Jacinto A, Parkhurst SM, et al. Live imaging of wound inflammation in Drosophila embryos reveals key roles for small GTPases during in vivo cell migration. J Cell Biol (2005) 168:567-73. doi:10.1083/jcb.200405120

48. Sminia T, Pietersma K, Scheerboom JE. Histological and ultrastructural observations on wound healing in the freshwater pulmonate Lymnaea stagnalis. Z Zellforsch Mikrosk Anat (1973) 141:561-73. doi:10.1007/BF00307125

49. Franchini A, Ottaviani E. Repair of molluscan tissue injury: role of PDGF and TGF-betal. Tissue Cell (2000) 32:312-21.

50. Rudolph R, Vande Berg J, Ehrlich PH. Wound contraction and scar contracture. In: Cohen IK, Diegelmann RF, Lindblad WJ, editors. Wound Healing; Biochemical and Clinical Aspects. (Vol. 6), Philadelphia, PA: Saunders (1992). p. 96-114.

51. Leibovich SJ, Ross R. The role of the macrophage in wound repair. Am J Pathol (1975) 78:71-100.

52. Pierce GF, Vande Berg J, Rudolph R, Tarpley J, Mustoe TA. Platelet-derived growth factor-BB and transforming growth factor $\beta$-1 selectively modulate glycosaminoglycans, collagen, and myofibroblasts in excisional wounds. Am J Pathol (1991) 138:629-46.

53. Quaglino D, Nanney LB, Ditesheim JA, Davidson JM. Transforming growth factor- $\beta$ stimulates wound healing and modulates extracellular matrix gene expression in pig skin. Incisional wound model. J Invest Dermatol (1991) 97:34-42.

54. Pongsomboon S, Tang S, Boonda S, Aoki T, Hirono I, Yasuike M, Tassanakajon A. Differentially expressed genes in Penaeus monodon hemocytes following infection with yellow head virus. BMB Rep (2008) 41:670-7. doi:10.5483/ BMBRep.2008.41.9.670

55. Cutroneo KR. TGF- $\beta$-induced fibrosis and SMAD signaling: oligo decoys as natural therapeutics for inhibition of tissue fibrosis and scarring. Wound Repair Regen (2007) 15(Suppl 1):S54-60. doi:10.1111/j.1524-475X.2007.00226.x

56. Jacobs W, Kumar-Singh S, Bogers J, Van de Vijver K, Deelder A, Van Marck E. Transforming growth factor- $\beta$, basement membrane components and heparan sulphate proteoglycans in experimental hepatic schistosomiasis mansoni. Cell Tissue Res (1998) 292:101-6. doi:10.1007/s004410051039

57. Blaxter ML. Molecular analysis of nematode evolution. In: Kennedy MW, Harnett W, editors. Parasitic Nematodes: Molecular Biology, Biochemistry and Immunology. St. Albans: CAB International (2001). p. 1-24.

58 . Wu G. Synthesis of citrulline and arginine from proline in enterocytes of postnatal pigs. Am J Physiol Gastrointest Liver Physiol (1997) 272:G1382-90.

59. Hamana K, Hamana H, Shinozawa T. Alterations in polyamine levels of nematode, earthworm, leech and planarian during regeneration, temperature and osmotic stresses. Comp Biochem Physiol B Biochem Mol Biol (1995) 111:91-7. doi:10.1016/0305-0491(94)00222-G

60. Zhang M, Wang H, Tracey KJ. Regulation of macrophage activation and inflammation by spermine: a new chapter in an old story. Crit Care Med (2000) 28(4 Suppl):N60-6. doi:10.1097/00003246-200004001-00007

61. Lockyer AE, Emery AM, Kane RA, Walker AJ, Mayer CD, Mitta G, et al. Early differential gene expression in haemocytes from resistant and susceptible Biomphalaria glabrata strains in response to Schistosoma mansoni. PLoS One (2012) 7(12):e51102. doi:10.1371/journal.pone.0051102

62. Albina JE, Caldwell MD, Henry WL, Mills CD. Regulation of macrophage functions by L-arginine. J Exp Med (1989) 169:1021-9. doi:10.1084/jem.169.3.1021

63. Witte MB, Barbul A. Arginine physiology and its implication for wound healing. Wound Repair Regen (2003) 11:419-23. doi:10.1046/j.1524-475X.2003.11605.x

64. Kinne O. Diseases of Marine Animals. Hamburg: Biologische Anstalt Helgoland (1983).

65. Ford SE, Kanaley SA, Littlewood DT. Cellular responses of oysters infected with Haplosporidium nelsoni: changes in circulating and tissue-infiltrating hemocytes. J Invertebr Pathol (1993) 61:49-57. doi:10.1006/jipa.1993.1009

66. Roberts AB, Heine UI, Flanders KC, Sporn MB. Transforming growth-factor$\beta$ - major role in regulation of extracellular-matrix. Ann N Y Acad Sci (1990) 580:225-32. doi:10.1111/j.1749-6632.1990.tb17931.x
67. Skugor S, Glover KA, Nilsen F, Krasnov A. Local and systemic gene expression responses of Atlantic salmon (Salmo salar) to infection with the salmon louse. BMC Genomics (2008) 9:498. doi:10.1186/1471-2164-9-498

68. McDowell IC, Nikapitiya C, Aguiar D, Lane CE, Istrail S, et al. Transcriptome of american oysters, Crassostrea virginica, in response to bacterial challenge: insights into potential mechanisms of disease resistance. PLoS One (2014) 9(8):e105097. doi:10.1371/journal.pone.0105097

69. Loke P, Gallagher I, Nair MG, Zang X, Brombacher F, Mohrs M, et al. Alternative activation is an innate response to injury that requires CD4+ T cells to be sustained during chronic infection. J Immunol (2007) 179:3926-36. doi:10.4049/jimmunol.179.6.3926

70. Wynn TA. Fibrotic disease and the TH1/TH2 paradigm. Nat Rev Immunol (2004) 4:583-94. doi:10.1038/nril412

71. Allen JE, Wynn T. Evolution of Th2 immunity: a rapid repair response to tissue destructive pathogens. PLoS Pathog (2011) 7(5):e1002003. doi:10.1371/ journal.ppat.1002003

72. Patel N, Kreider T, Urban JF Jr, Gause WC. Characterisation of effector mechanisms at the host: parasite interface during the immune response to tissue-dwelling intestinal nematode parasites. Int J Parasitol (2009) 39:13-21. doi:10.1016/j.ijpara.2008.08.003

73. Pearce EJ, Vasconcelos JP, Brunet LR, Sabin EA. IL-4 in schistosomiasis. Exp Parasitol (1996) 84:295-9. doi:10.1006/expr.1996.0116

74. Dzik JM, Gołos B, Jagielska E, Zielinski Z, Wałajtys-Rode E. A non-classical type of alveolar macrophage response to Trichinella spiralis infection. Parasite Immunol (2004) 26:197-205. doi:10.1111/j.0141-9838.2004.00700.x

75. Bai X, Wu X, Wang X, Guan Z, Gao F, Yu J. et al. Regulation of cytokine expression in murine macrophages stimulated by excretory/secretory products from Trichinella spiralis in vitro. Mol Cell Biochem (2012) 360:79-88. doi:10.1007/s11010-011-1046-4

76. Du L, Wei H, Li L, Shan H, Yu Y, Wang Y, et al. Regulation of recombinant Trichinella spiralis $53-\mathrm{kDa}$ protein (rTsP53) on alternatively activated macrophages via STAT6 but not IL-4R $\alpha$ in vitro. Cell Immunol (2014) 288:1-7. doi:10.1016/j.cellimm.2014.01.010

77. Donnelly S, Stack CM, O'Neill SM, Sayed AA, Williams DL, Dalton JP. Helminth 2-Cys peroxiredoxin drives Th2 responses through a mechanism involving alternatively activated macrophages. FASEB J (2008) 22:4022-32. doi:10.1096/fj.08-106278

78. Tanabe M, Kaneko N, Takeuchi T. Schistosoma mansoni: higher free proline levels in the livers of infected mice. Exp Parasitol (1991) 72:134-44. doi:10.1016/0014-4894(91)90131-F

79. Atochina O, Da'dara AA, Walker M, Harn DA. The immunomodulatory glycan LNFPIII initiates alternative activation of murine macrophages in vivo. Immunology (2008) 125:111-21. doi:10.1111/j.1365-2567.2008.02826.x

80. Thomas PG, Carter MR, Da'dara AA, DeSimone TM, Harn DA. A helminth glycan induces APC maturation via alternative NF- $\kappa \mathrm{B}$ activation independent of I $\kappa \mathrm{B} \alpha$ degradation. J Immunol (2005) 175:2082-90. doi:10.4049/jimmunol. 175.4.2082

81. Jensen KD, Wang Y, Wojno ED, Shastri AJ, Hu K, Cornel L, et al. Toxoplasma polymorphic effectors determine macrophage polarization and intestinal inflammation. Cell Host Microbe (2011) 9:472-83. doi:10.1016/j.chom. 2011.04.015

82. Clark RI, Woodcock KJ, Geissmann F, Trouillet C, Dionne MS. Multiple TGF$\beta$ superfamily signals modulate the adult Drosophila immune response. Curr Biol (2011) 21:1672-7. doi:10.1016/j.cub.2011.08.048

83. Bootcov MR, Bauskin AR, Valenzuela SM, Moore AG, Bansal M, He XY. MIC-1, a novel macrophage inhibitory cytokine, is a divergent member of the TGF- $\beta$ superfamily. Proc Natl Acad Sci U S A (1997) 94:11514-9. doi:10.1073/pnas.94.21.11514

84. Shull MM, Ormsby I, Kier AB, Pawlowski S, Diebold RJ, Yin M, et al. Targeted disruption of the mouse transforming growth factor- $\beta 1$ gene results in multifocal inflammatory disease. Nature (1992) 359:693-9. doi:10.1038/359693a0

85. Mallo GV, Kurz CL, Couillault C, Pujol N, Granjeaud S, Kohara Y, et al. Inducible antibacterial defense system in C. elegans. Curr Biol (2002) 12:1209-14. doi:10.1016/S0960-9822(02)00928-4

86. Gong D, Shi W, Yi SJ, Chen H, Groffen J, Heisterkamp N. TGF- $\beta$ signaling plays a critical role in promoting alternative macrophage activation. BMC Immunol (2012) 13:31. doi:10.1186/1471-2172-13-31

87. Mu Y, Gudey SK, Landstrom M. Non-Smad signaling pathways. Cell Tissue Res (2012) 347:11-20. doi:10.1007/s00441-011-1201-y 
88. Rocher C, Singla DK. SMAD-PI3K-Akt-mTOR pathway mediates BMP7 polarization of monocytes into M2 macrophages. PLoS One (2013) 8(12):e84009. doi:10.1371/journal.pone.0084009

89. Rauh MJ, Ho V, Pereira C, Sham A, Sly LM, Lam V, et al. SHIP represses the generation of alternatively activated macrophages. Immunity (2005) 23:361-74. doi:10.1016/j.immuni.2005.09.003

90. Weichhart T, Säemann MD. The PI3K/Akt/mTOR pathway in innate immune cells: emerging therapeutic applications. Ann Rheum Dis (2008) 67(Suppl 3):iii70-4. doi:10.1136/ard.2008.098459

91. Miyazono K, Maeda S, Imamura T. BMP receptor signaling: transcriptional targets, regulation of signals, and signaling cross-talk. Cytokine Growth Factor Rev (2005) 16:251-63. doi:10.1016/j.cytogfr.2005.01.009

92. Lu M, Lin SC, Huang Y, Kang YJ, Rich R, Lo YC, et al. XIAP induces NF-кB activation via the BIR1/TAB1 interaction and BIR1 dimerization. Mol Cell (2007) 26:689-702. doi:10.1016/j.molcel.2007.05.006

93. Hong JH, Lee GT, Lee JH, Kwon SJ, Park SH, Kim SJ, et al. Effect of bone morphogenetic protein-6 on macrophages. Immunology (2009) 128(1 Suppl):e442-50. doi:10.1111/j.1365-2567.2008.02998.x

94. Fujihara M, Muroi M, Tanamoto K, Suzuki T, Azuma H, Ikeda H. Molecular mechanisms of macrophage activation and deactivation by lipopolysaccharide: roles of the receptor complex. Pharmacol Ther (2003) 100:171-94 doi:10.1016/j.pharmthera.2003.08.003

95. Kwon SJ, Lee GT, Lee JH, Kim WJ, Kim IY. Bone morphogenetic protein6 induces the expression of inducible nitric oxide synthase in macrophages. Immunology (2009) 128(1 Suppl):e758-65. doi:10.1111/j.1365-2567.2009. 03079.x

96. Shibuya H, Iwata H, Masuyama N, Gotoh Y, Yamaguchi K, Irie K, et al. Role of TAK1 and TAB1 in BMP signaling in early Xenopus development. EMBO J (1998) 17:1019-28. doi:10.1093/emboj/17.4.1019

97. Jadrich JL, O'Connor MB, Coucouvanis E. Expression of TAK1, a mediator of TGF- $\beta$ and BMP signaling, during mouse embryonic development. Gene Expr Patterns (2003) 3:131-4. doi:10.1016/S1567-133X(03)00012-7

98. Wang C, Deng L, Hong M, Akkaraju GR, Inoue J, Chen ZJ. TAK1 is a ubiquitin-dependent kinase of MKK and IKK. Nature (2001) 412:346-51. doi:10.1038/35083684

99. Mills CD. M1 and M2 Macrophages: Oracles of Health and Disease. Crit Rev Immunol (2012) 32(6):463-88. doi:10.1615/CritRevImmunol.v32.i6.10

100. Kleinert H, Schwarz PM, Forstermann U. Regulation of the expression of inducible nitric oxide synthase. Biol Chem (2003) 384:1343-64. doi:10.1515/ BC. 2003.152

101. Knowles RG, Moncada S. Nitric oxide synthases in mammals. Biochem J (1994) 298:249-58.

102. Zemojtel T, Wade RC, Dandekar T. In search of the prototype of nitric oxide synthase. FEBS Lett (2003) 554:1-5. doi:10.1016/S0014-5793(03) 01081-0

103. Adak S, Aulak KS, Stuehr DJ. Direct evidence for nitric oxide production by a nitric-oxide synthase-like protein from Bacillus subtilis. J Biol Chem (2002) 277:16167-71. doi:10.1074/jbc.M201136200

104. Moroz LL, Meech RW, Sweedler JV, Mackie GO. Nitric oxide regulates swimming in the jellyfish Aglantha digitale. J Comp Neurol (2004) 471:26-36. doi:10.1002/cne.20023

105. Cristino L, Guglielmotti V, Cotugno A, Musio C, Santillo S. Nitric oxide signaling pathways at neural level in invertebrates: functional implications in cnidarians. Brain Res (2008) 1225:17-25. doi:10.1016/j.brainres.2008. 04.056

106. Trimmer BA, Aprille J, Modica-Napolitano J. Nitric oxide signalling: insect brains and photocytes. Biochem Soc Symp (2004) 71:65-83.

107. Kohn AB, Lea JM, Moroz LL, Greenberg RM. Schistosoma mansoni: use of a fluorescent indicator to detect nitric oxide and related species in living parasites. Exp Parasitol (2006) 113:130-3. doi:10.1016/j.exppara.2005. 12.013

108. Elofsson R, Carlberg M, Moroz L, Nezlin L, Sakharov D. Is nitric oxide (NO) produced by invertebrate neurones? Neuroreport (1993) 4:279-82. doi:10.1097/00001756-199303000-00013

109. Yuda M, Hirai M, Miura K, Matsumura H, Ando K, Chinzei Y. cDNA cloning, expression and characterization of nitric-oxide synthase from the salivary glands of the blood-sucking insect Rhodnius prolixus. Eur J Biochem (1996) 242:807-12. doi:10.1111/j.1432-1033.1996.0807r.x
110. Nighorn A, Gibson NJ, Rivers DM, Hildebrand JG, Morton DB. The nitric oxide-cGMP pathway may mediate communication between sensory afferents and projection neurons in the antennal lobe of Manduca sexta. J Neurosci (1998) 18:7244-55.

111. Regulski M, Tully T. Molecular and biochemical characterization of dNOS: a Drosophila $\mathrm{Ca}^{2+} /$ calmodulin-dependent nitric oxide synthase. Proc Natl Acad Sci U S A (1995) 92:9072-6. doi:10.1073/pnas.92.20.9072

112. Korneev SA, Piper MR, Picot J, Phillips R, Korneeva EI, O’Shea M. Molecular characterization of NOS in a mollusc: expression in a giant modulatory neuron. J Neurobiol (1998) 35:65-76. doi:10.1002/(SICI)1097-4695(199804) 35:1<65::AID-NEU6>3.0.CO;2-9

113. Moroz LL, Kohn AB. Parallel evolution of nitric oxide signaling: diversity of synthesis \& memory pathways. Front Biosci (2014) 16:2008-51. doi:10.2741/ 3837

114. Golderer G, Werner ER, Leitner S, Grobner P, Werner-Felmayer G. Nitric oxide synthase is induced in sporulation of Physarum polycephalum. Genes Dev (2001) 15:1299-309. doi:10.1101/gad.890501

115. Dzik JM. The ancestry and cumulative evolution of immune reactions. Acta Biochim Pol (2010) 57:443-66.

116. Yeh FC, Wu SH, Lai CY, Lee CY. Demonstration of nitric oxide synthase activity in crustacean hemocytes and anti-microbial activity of hemocyte-derived nitric oxide. Comp Biochem Physiol B Biochem Mol Biol (2006) 144:11-7. doi:10.1016/j.cbpb.2006.01.007

117. Palumbo A. Nitric oxide in marine invertebrates: a comparative perspective. Comp Biochem Physiol A Mol Integr Physiol (2005) 142:241-8. doi:10.1016/j. cbpb.2005.05.043

118. Nappi AJ, Vass E, Frey F, Carton Y. Nitric oxide involvement in Drosophila immunity. Nitric Oxide (2000) 4:423-30. doi:10.1006/niox.2000.0294

119. Foley E, O'Farrell PH. Nitric oxide contributes to induction of innate immune responses to gram-negative bacteria in Drosophila. Genes Dev (2003) 17:115-25. doi:10.1101/gad.1018503

120. Dimopoulos G, Seeley D, Wolf A, Kafatos FC. Malaria infection of the mosquito Anopheles gambiae activates immune-responsive genes during critical transition stages of the parasite life cycle. EMBO J (1998) 17:6115-23. doi:10.1093/emboj/17.21.6115

121. Luckhart S, Rosenberg R. Gene structure and polymorphism of an invertebrate nitric oxide synthase gene. Gene (1999) 232:25-34. doi:10.1016/S03781119(99)00121-3

122. Beschin A, Bilej M, Torreele E, De Baetselier P. On the existence of cytokines in invertebrates. Cell Mol Life Sci (2001) 58(5-6):801-14. doi:10.1007/ PL00000901

123. Lowenstein CJ, Alley EW, Raval P, Snowman AM, Snyder SH, Russell SW, et al Macrophage nitric oxide synthase gene: two upstream regions mediate induction by interferon gamma and lipopolysaccharide. Proc Natl Acad Sci U S A (1993) 90:9730-4. doi:10.1073/pnas.90.20.9730

124. Xie QW, Whisnant R, Nathan C. Promoter of the mouse gene encoding calcium-independent nitric oxide synthase confers inducibility by interferon gamma and bacterial lipopolysaccharide. J Exp Med (1993) 177:1779-84. doi:10.1084/jem.177.6.1779

125. Sengupta R, Sahoo R, Mukherjee S, Regulski M, Tully T, Stuehr DJ, et al. Characterization of Drosophila nitric oxide synthase: a biochemical study. Biochem Biophys Res Commun (2003) 306:590-7. doi:10.1016/S0006-291X(03) 01003-9

126. Ghosh DK, Wu C, Pitters ER, Mayer B, Stuehr DJ. Characterization of the inducible nitric oxide synthase oxygenase domain identifies a 49 -amino acid segment required for subunit dimerization and tetrahydrobiopterin interaction. Biochemistry (1997) 36:10609-19. doi:10.1021/bi9702290

127. Pace JL, Lowenstein CJ, Phillips TA, Chen LC, Morrison DC, Hunt JS, et al. Population dynamics of inducible nitric oxide synthase production by LPSand LPS/IFN-gamma-stimulated mouse macrophages. J Endotoxin Res (1994) 1:227-33.

128. Xie QW, Kashiwabara Y, Nathan C. Role of transcription factor NF-к B/Rel in induction of nitric oxide synthase. J Biol Chem (1994) 269:4705-8.

129. Vodovotz Y. Control of nitric oxide production by transforming growth factorbetal: mechanistic insights and potential relevance to human disease. Nitric Oxide (1997) 1:3-17. doi:10.1006/niox.1996.0105

130. Sugiyama Y, Kakoi K, Kimura A, Takada I, Kashiwagi I, Wakabayashi Y. Smad2 and Smad3 are redundantly essential for the suppression of iNOS synthesis 
in macrophages by regulating IRF3 and STAT1 pathways. Int Immunol (2012) 24:253-65. doi:10.1093/intimm/dxr126

131. Vodovotz Y, Chesler L, Chong H, Kim SJ, Simpson JT, De Graff W, et al. Regulation of transforming growth factor betal by nitric oxide. Cancer Res (1999) 59:2142-9.

132. Forlenza M, Fink IR, Raes G, Wiegertjes GF. Heterogeneity of macrophage activation in fish. Dev Comp Immunol (2011) 35:1246-55. doi:10.1016/j.dci.2011. 03.008

Conflict of Interest Statement: The author declares that the research was conducted in the absence of any commercial or financial relationships that could be construed as a potential conflict of interest.
Received: 21 August 2014; paper pending published: 23 September 2014; accepted: 13 October 2014; published online: 07 November 2014.

Citation: Dzik JM (2014) Evolutionary roots of arginase expression and regulation. Front. Immunol. 5:544. doi: 10.3389/fimmu.2014.00544

This article was submitted to Molecular Innate Immunity, a section of the journal Frontiers in Immunology.

Copyright $(2014$ Dzik. This is an open-access article distributed under the terms of the Creative Commons Attribution License (CC BY). The use, distribution or reproduction in other forums is permitted, provided the original author(s) or licensor are credited and that the original publication in this journal is cited, in accordance with accepted academic practice. No use, distribution or reproduction is permitted which does not comply with these terms. 